\title{
Xenobiotic excretion in fish with aglomerular kidneys
}

\author{
Jørgen S. Christiansen ${ }^{1, *}$, Roy A. Dalmo ${ }^{2}$, Kristian Ingebrigtsen ${ }^{3}$ \\ 'Centre of Aquaculture, Norwegian Institute of Fisheries and Aquaculture, Tromse, Norway \\ ${ }^{2}$ Department of Experimental Pathology and Anatomy, Institute of Medical Biology, University of Tromsø, Tromsø, Norway \\ ${ }^{3}$ Department of Pharmacology, Microbiology and Food Hygiene, Norwegian College of Veterinary Medicine, Oslo, Norway, and \\ Department of Pharmacology and Toxicology, Swedish University of Agricultural Sciences, Uppsala, Sweden
}

\begin{abstract}
Foreign chemicals in teleost fish are primarily excreted via urine and bile. Xenobiotics and their metabolites excreted via urine are filtered in the glomerulus and/or secreted by tubular transport within the kidney. Contrary to most fish species, such as the Atlantic cod Gadus morhua, the polar cod Boreogadus saida displays a complete absence of the glomerular apparatus. We examined the excretory routes in an aglomerular ( $B$. saida) vs a glomerular (G. morhua) gadoid fish. Using an inert polysacharride as a model compound, it is demonstrated that this xenobiotic is excreted solely via the urine in $G$. morhua and via the bile in $B$. saida.
\end{abstract}

KEY WORDS: Polar fish A Aglomerular kidney Xenobiotic excretion - Environmental pollutants

The nephron is the structural and functional unit of the vertebrate kidney. It is basically segmental, comprising the renal corpuscle (glomerulus) and the renal tubulus which is linked to the urinary bladder via the collecting system (Dantzler 1988). This basic pattern may be highly modified according to the habitat and mode of life displayed by teleost fish (Hentschel \& Elger 1992). Histomorphological analysis of the kidney from Gadus morhua showed that glomeruli were numerous and appeared to be well developed. By contrast, our examination of the kidney from Boreogadus saida revealed a complete lack of glomeruli (J. S. Christiansen, A. B. Amin \& K. Ingebrigtsen unpubl.). Although aglomerular nephrons have not previously been reported for a true Arctic fish species, the evolution of aglomerularism is a well-known phenomenon amongst the Antarctic notothenioids (Eastman 1993 and references therein). Aglomerular nephrons in Antarctic fish have been suggested to represent an adaptation to reduce water efflux and to prevent the loss of low molecular weight compounds such

•E-mail: jorgensc@fiskforsk.norut.nor as the vital antifreezes (Dobbs et al. 1974). Likewise, the absence of glomeruli may be regarded as a protective mechanism in $B$. saida, which survival also depends on antifreezes in systemic circulation (Osuga \& Feeney 1978).

Laminaran is a water-soluble polysaccharide (mol. wt. $-4.5 \mathrm{kDa}$ ) that is readily excreted into the urine in both mammals and fish. Tritiated laminaran was administered into the caudal vein of both Gadus morhua and Boreogadus saida ( $\mathrm{n}=4$ for each species) in order to trace excretory routes for this particular xenobiotic using tape-section autoradiography and radiochromatographic analysis (Sephadex G-25 gel) (Dalmo et al. 1994). The results were unequivocal (Fig. 1). In G. morhua, laminaran was excreted exclusively in the urine. This was in sharp contrast to the aglomerular $B$. saida in which laminaran was concentrated in the bile but not in the urine.

The inability of aglomerular fish to perform ultrafiltration implies that urinary excretion of xenobiotics and their metabolites may be hampered (Pritchard \& Bend 1984). This, in turn, may result in an increased hepato-biliar excretion of such compounds. The toxic properties and the retention time of xenobiotics excreted via bile may be significantly affected due to bioactivation mediated by the intestinal microflora and reabsorption (Bakke et al. 1982). Consequently, although highly advantageous for fish dependent on antifreezes, aglomerular nephrons may represent a disadvantage when xenobiotics are introduced into the environment.

There is reason to believe that the Arctic marine ecosystem is being increasingly loaded with various xenobiotics from industrial discharges transported into the Arctic, and due to human activities in the Arctic itself (Christiansen \& George 1995, Stange \& Klungsøyr 1995). Gadoid fish are a major component in Arctic marine food-webs and Boreogadus saida is 


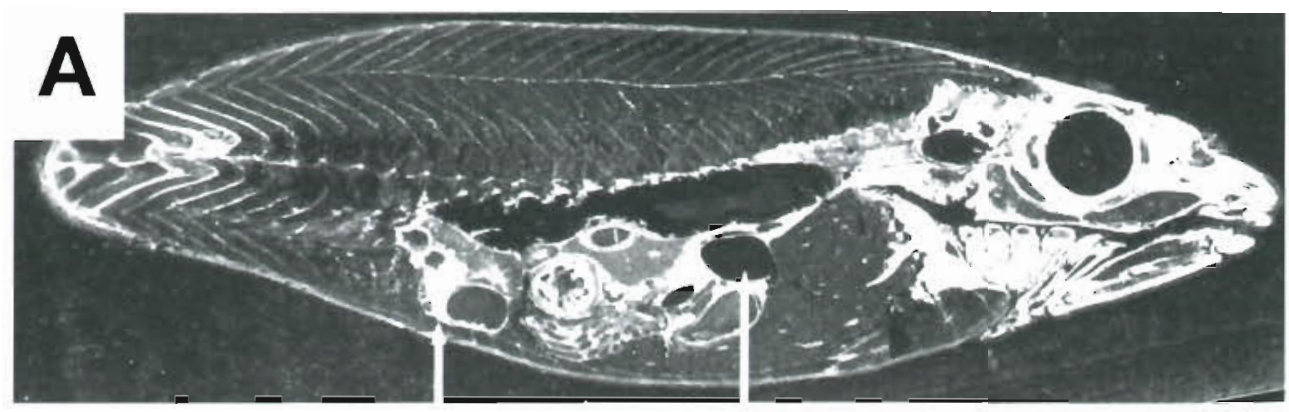

URINE

BILE

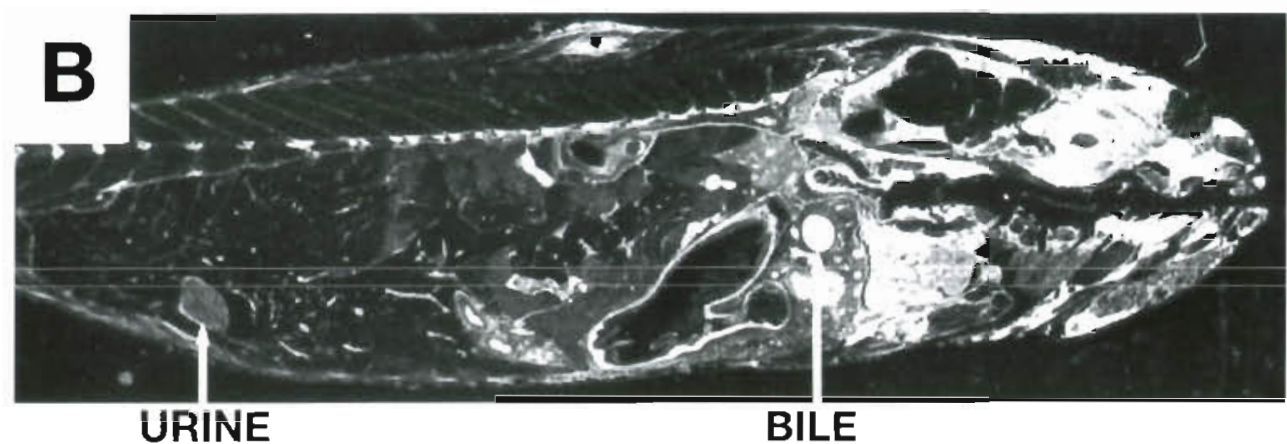

Fig. 1. Tape-section autoradiograms (section thickness: $30 \mu \mathrm{m}$; exposure time: $2 \mathrm{mo}$ ) of (A) Atlantic cod Gadus morhua and (B) polar cod Boreogadus saida $72 \mathrm{~h}$ after intravenous administration of ${ }^{3} \mathrm{H}$-laminaran (12 $\mathrm{mg} ; 36 \mathrm{MBq} \mathrm{kg}^{-1}$ body weight). White areas correspond to high concentrations of radiolabelled compound. Wild $B$. saida (body size $\sim 50 \mathrm{gl}$, collected in the Pechora Sea, Russia $\left(70^{\circ} \mathrm{N}, 54^{\circ} \mathrm{E}\right)$, were acclimated to full strength sea water at a constant temperature of approximately $0^{\circ} \mathrm{C}(\mathrm{Ch}$ ristiansen 1995). Artificially raised G. morhua (body size $\sim 50 \mathrm{~g}$ ) originated from a local stock near Tromsø, Norway, and were held under similar conditions as $B$. saida at an ambient temperature of about $5^{\circ} \mathrm{C}$

recognized as the piscine key species inhabiting the subzero waters of the Arctic Ocean (Hobson \& Welch 1992). Therefore, we urge that the specialized renal anatomy and physiology displayed by $B$. saida (as well as other polar fish species) should be contemplated in future studies aimed at assessing the biological impact of environmental pollutants in the polar oceans.

\section{LITERATURE CITED}

Bakke JE, Bergman AL, Larsen GL (1982) Metabolism of 2,4', 5 -tnchlorobiphenyl by the mercapturic acid pathway. Science 217:645-647

Christiansen JS (1995) Food consumption and growth rate variations in male and female polar cod (Boreogadus saida). Comm Meet Int Coun Explor Sed CM-KES/P:9

Christiansen JS, George SG (1995) Contamination of food by crude oil affects food selection and growth performance, but not appetite, in an Arctic fish, the polar cod (Boreogadus salda). Polar Biol 15:277-281

This note was submitted to the editor
Dalmo RA, Ingebrigtsen K, Horsberg TE, Seljelid R (1994) Intestinal absorption of immunomodulatory laminaran and derivatives in Atlantic salmon, Salmo salar L. J Fish Dis 17:579-589

Dantzler WH (1988) Comparative physiology of the vertebrate kidney. Springer-Verlag, Berlin

Dobbs GH, Lin Y, DeVries AL (1974) Aglomerularism in Antarctic fish. Science 185:793-794

Eastman JT (1993) Antarctic fish biology. Academic Press, San Diego

Hentschel H, Elger M (1992) The vertebrate kidney: a comparative approach. Verh Dtsch Zool Ges 85:297-314

Hobson KA, Welch HE (1992) Determination of trophic relationships within a high Arctic marine food web using $\delta^{13} \mathrm{C}$ and $\delta^{15} N$ analysis. Mar Ecol Prog Ser 84:9-18

Osuga DT, Feeney RE (1978) Antifreeze glycoproteins from Arctic fish. J Biol Chem 253:5338-5343

Pritchard JB, Bend J (1984) Mechanisms controlling the renal excretion of xenobiotics in fish: effects of chemical structure. Drug Metabolism Rev 15:655-671

Stange K, Klungsøyr J (1995) Baseline study of contaminants in the Barents Sea. Fisken Havet 8

Manuscript first received: January 8,1996

Revised version accepted: April 17, 1996 